\title{
Fintech in Dubai: Development and Ecosystem
}

\author{
Daniele Schilirò $^{1}$ \\ ${ }^{1}$ Department of Economics, University of Messina, Messina, Italy \\ Correspondence: Daniele Schilirò, Department of Economics, University of Messina, Messina, Piazza Pugliatti, \\ 1,98122 , Italy.
}

Received: September 14, 2021

Accepted: October 11, 2021

Online Published: October 19, 2021

doi:10.5539/ibr.v14n11p61

URL: https://doi.org/10.5539/ibr.v14n11p61

\begin{abstract}
This paper focuses on Dubai's positive attitude toward the digital transformation of the financial sector and the development of fintech due to the growth of financial technology. After a review of the fintech literature, the paper highlights Dubai's dynamic financial ecosystem, including the diffusion of innovative digital technologies related to fintech. Among the main factors explaining the unstoppable growth of financial technology in Dubai are a flourishing of innovative fintech startups that have revolutionized the financial service sector, a private sector interested in partnering with financial ventures, an appropriate regulatory regime, and updated to the evolution of fintech, and supportive government policies. Regarding Dubai's post-COVID efforts toward the digital transformation of the financial sector, the paper argues that the emirate's fintech ecosystem represents a challenging paradigm for the business world.
\end{abstract}

Keywords: fintech, ecosystem, Dubai, digital technologies, financial services

JEL Classification: G23, G28, O30

\section{Introduction}

The digital transformation of the financial sector is a global phenomenon. A glaring consequence of the adoption of digital technologies in the financial sector is the growth of financial technology (fintech). The start of the fintech rush coincided with the cryptocurrency boom. The popularity of virtual currencies succeeded in bringing out the most innovative technologies related to money. Crucial innovations in the financial system are a natural consequence of the need for more accessibility. The rise of fintech has led to changes in the role of technology, which involves major changes in consumer behavior, ecosystems, and regulation. In this new paradigm (Lee \& Shin, 2018), innovators and disruptors are the key players of the fintech revolution.

Fintech has experienced tremendous growth in Dubai in recent years with a significant increase in startups, strong demand for innovation, and a transformation of the financial ecosystem.

Overall, this paper aims to contribute to the emerging literature on fintech. Specifically, it is a contribution to the literature on fintech in the UAE. The purpose of the paper is to provide a better understanding of the fintech ecosystem and its evolution in Dubai.

First, the paper explains the methodology adopted. Second, it provides a survey of the literature of fintech. Third, the study focuses on fintech in Dubai, emphasizing the contribution of major factors to the development of the fintech ecosystem. Fourth, the study examines Dubai's financial services regulations and regulators. Discussion and conclusions end the paper.

\section{Methodology}

This paper represents a theoretical and conceptual study of fintech. It discusses the emergence of financial technology favored by the rise and diffusion of digital technologies. This contribution provides a review of the literature of fintech quite comprehensive, though not exhaustive, and analyzes the characteristics of the fintech sector. Particularly, it provides an overview and assessment of fintech in Dubai. The paper examines the development of fintech in the emirate and the structure and evolution of its ecosystem. Our analysis, although largely theoretical, provides descriptive empirical evidence through some significant fintech data. 


\section{Literature Review}

A typical definition of fintech, although there are many, is suggested by Gomber, Koch, \& Siering (2017), who define fintech as a neologism coming from "financial" and "technology," referring to the connection between modern Internet technologies and business activities of the banking sector.

Most definitions in the literature are characterized by two hallmarks: the focus on a new market entrant and disruptive innovation (Breidbach, Keating \& Lim, 2020, p.82). In particular, Gomber, Kauffman, Parker, \& Weber (2018) emphasize the concept of "fintech revolution," noting that fintech encompasses a new sector in the finance industry characterized by innovators and disruptors, which are constituted by new market entrants. New fintech start-ups aim to implement successful business models and create an enhanced customer experience. These authors use the term "digital finance" to describe the digitalization of the financial sector from an incumbent's perspective. The result of these changes and transformations is that fintech enables efficiency improvements, ensures customer centricity, and leads to better transparency in financial services.

Lee \& Shin (2018) also point out that fintech brings about a new paradigm in the financial sector. Driven primarily by information technology, and, in part, by the sharing economy and favorable regulation, these authors argue that fintech aims to "reshape the financial industry by cutting costs, improving the quality of financial services, and creating a more diverse and stable financial landscape." (p. 35)

Gozman, Liebenau, \& Mangan (2018) and Iman (2020) argue that digital technology spurred financial services with new waves of innovation, so fintech emerged as the natural solution to the demand for rapid digitalization and impacted consumer behaviors, ecosystems, and regulation.

Haddad \& Hornuf (2019) investigate the factors influencing the formation of fintech startups in 55 countries. In their empirical analysis regarding the country-level factors that drive the formation of new startups, these authors confirm their hypothesis that in well-developed economies GDP per capita and VC financing variables are strong and robust predictors of fintech startup formation. Haddad \& Hornuf (2019) find that fintech startup formation occurs more frequently in countries where supporting infrastructure is readily available. Another significant finding is that fintech startups are more frequent in countries with flexible market regulations. Fintech startups often prefer to follow a strategy of cooperation with established financial organizations, technology firms, and large ecosystems. Haddad \& Hornuf (2019) also point out that attract a critical mass of highly specialized individuals is critical to establish a fintech ecosystem. They warn that, although investments in fintech are growing, returns in some fintech market segments might remain small.

Lee \& Shin (2018) focus on the fintech ecosystem and observe that through the combination of e-finance, Internet technologies, social network services, social media, artificial intelligence and big data analytics, fintech innovation has emerged. Fintech startups have become able to develop and deliver a range of innovative financial services like digital payment solutions, brokerage services with retail customers, asset management, and financial risk management.

Lee \& Shin (2018) identify five elements that characterize the fintech ecosystem. They are fintech startups (e. g. payment, wealth management, lending, crowdfunding, capital market, etc.) that are at the center of the ecosystem. These startups usually target niche markets, incur lower operating costs, and provide more personalized services than traditional financial firms, also driving the phenomenon of unbundling financial services. Technology developers are the second important element of the ecosystem. They provide digital platforms for social media, big data analytics, cloud computing, artificial intelligence, and mobile services. The third element is government. Depending on the national economic development plans and economic policies, governments provide different levels of regulation for fintech startups and can facilitate financial competitiveness. Lee \& Shin (2018) note that: "The looser regulatory requirements imposed on fintech startups allow them to provide more customized, inexpensive, and easy-to-access financial services to customers than traditional institutions." (p.38) Financial customers (e. g. individuals and organizations) are the fourth element of the ecosystem and the source of revenue generation for fintech firms. Usually, fintech companies target individual customers and small and medium enterprises. Finally, traditional financial institutions are also a driving force in the fintech ecosystem. These institutions have changed their business models, developing strategies with the inclusion of fintech innovation and partnering with fintech startups through financing agreements.

Alaassar, Mention, \& Aas (2021) also focus on the ecosystem. In particular, they explore the ecosystem actor interactions within the fintech entrepreneurial ecosystem (EE). They note that fintech is characterized by the proliferation of newcomers, financial stability risks, and changes in the regulatory environment. The focus on fintech is justified by the emergence of digitalization. Especially in the financial sector, digitalization has enabled fintech newcomers to aggressively penetrate the market, forcing traditional financial institutions to 
become more open to market engagement through strategic alliances. Alaassar, Mention, \& Aas (2021) aim to shed light on how different ecosystem actors contribute to the creation of new ventures in the fintech sector. (Note 1) These authors, inspired by the conceptualization of ecosystem dynamics suggested by Brown \& Mason (2017), look at the underlying dynamics of four categories: entrepreneurial actors, resource providers, connectors, and entrepreneurial culture. In their view, the role of entrepreneurial actors is crucial for the growth of ecosystems, due to their spillover effects (e. g. transfer of knowledge, startup spirit, and other resources); also, the level of competence of entrepreneurial actors is raised by the presence and quality of universities and research institutions. The findings of the empirical investigation by Alaassar, Mention, \& Aas (2021) reveal that business incubators and accelerators play an intermediary role between ecosystem actors and fintech entrepreneurs. Venture capitalists (VCs) also play a substantial role in helping startups access networks and resources. In addition, they find that culture and level of knowledge are fundamental to the development dynamics of the ecosystem, especially in emerging areas as cryptocurrency, blockchain, and cybersecurity. Regarding the regulatory environment, these authors find the absence of uniformity between regulators and different levels of regulation in the various areas. In addition, regulators can ensure the right governance between ecosystem actors also affecting the development of fintech innovation. Similar considerations regarding VC's investments in fintech are made by Cornelli, Doerr, Franco \& Frost (2021). They point out that VC investments in fintech far outpaced the growth of non-fintech deals at the global level, where cryptocurrency and blockchain, big data, AI, and machine learning dominate the funding landscape. Moreover, these authors, through their empirical analysis, find that fintech firms raise more capital in countries with better regulatory quality, higher financial development, and greater innovation capacity.

Agur, Martinez Peira, \& Roschon (2020) note that in the financial sector a process of streamlining existing infrastructure and creating new solutions is underway. Also, they underline that fintech involves new solutions built on digital platforms, cloud computing, distributed ledger technologies (DLTs), spanning mobile payments, crypto-assets, and peer-to-peer (P2P) applications. Fintech's phase of rapid development is marked by the proliferation of startups and other new entrants, such as information technology (IT) and e-commerce firms that have fragmented the financial services market. Fintech companies are built on a model of agility, flexibility, and innovation. The adoption of digital identity (ID) technologies is helping to expand the benefits of fintech across the entire financial sector.

Moreover, these innovative digital activities are disrupting the course of traditional banking. Thus, consumer banking is moving from a physical to a digital environment as digitalization in financial services enables a distributed, open, and customer-centric banking system. Today, customers are becoming interested in a platform that offers the most efficient, simple process for borrowing, budgeting, saving, or investing. These new platforms low-cost tech platforms can open access to the financial markets to a wide range of investors.

Zhang et al. (2016); Pousttchi \& Dehnert (2018) point out that fintech offerings are challenging the status quo of mainstream banking. Fintech companies are expanding products and financial services to banking customers thanks to their agile structures. (Note 3) As the alternative finance market grows, fintech firms tend to offer new products and services to satisfy those customers' needs not previously addressed by traditional financial service firms. At the same time, customers continue to demand more flexibility and ownership of their financial data, wanting their banks to meet them where they are (via their specific apps). This evolution integrates banking services and customer data in third-party applications. Open banking meets these needs through application program interfaces (APIs); (Note 2) it allows secure access to bank data and the sharing of data between players in the banking ecosystem as authorized by the customers. (Note 4) Thus, open banking is becoming a major strategy for banks as the banking and payment system. (Note 5)

Breidbach, Keating, \& Lim (2020), like Lee \& Shin (2018), highlight that fintech companies can unbundle the offering of financial services through new technologies because they are less dependent on regulatory constraints and have a higher willingness to take risks. OECD (2020) highlights the efficiency of fintech, arguing that fintech firms can more effectively screen candidate borrowers via statistical models based on big data. This initiative, thereby, overcomes the information asymmetries at the root of the banking business. Fintech companies can also benefit from designing systems in the cloud from scratch instead of working on top of IT legacy systems. In addition, fintech companies can increase financial inclusion by opening the door to financial services for segments of the population and small-to-medium-sized enterprises (SMEs) currently unserved or underserved by banks. Its potential appears to be huge. Goldstein, Jagtiani, \& Klein (2019) point out that fintech could benefit underserved consumers around the globe by allowing approximately 2 billion unbanked consumers to be connected to the financial system. Fintech firms can cut costs (e.g., financial intermediation costs in lending, payment systems, and financial advising) and improve the quality of financial services. This is because they have 
no legacy technologies, are characterized by a culture of efficient operational design, and are free from the need to protect existing businesses. Also, fintech startups are familiar with remote work and teams. This is boosted by the increased demand for digital solutions, which stimulates investors' interest in them.

However, Lukonga (2018) suggests that the sustainable development of fintech requires enabling environments. There is a need for a business-friendly environment, laws to provide legal certainty, prudential regulations that address fintech specific risks, venture and growth capital, talent in technology and finance, initial public offerings (IPO) markets to facilitate investors who want to exit initial investments and markets that create demand.

As we have shown in this section, fintech firms are radically changing the financial industry and its ecosystem. The emerging fintech ecosystem is a network of relationships between financial services companies, fintech startups, government and financial regulators, tech leaders, and the investment community. Such a fintech ecosystem is changing and moving quickly across the world. Dubai, as will be shown in the next section, is a leading city in this major transformation.

\section{Fintech Growth and Ecosystem in Dubai}

This section analyzes the growth of the fintech sector in Dubai. It also explores the evolution of the fintech ecosystem in the emirate.

Dubai is a leading financial and commercial hub in the United Arab Emirates (UAE), the Middle East, and beyond. The emirate is an example of a successful transition toward a diversified knowledge economy (Schilirò, 2013). Dubai, as a major international service economy, follows a pro-business economic development model, emphasizing market liberalism and economic openness while embracing globalization. As Mishrif \& Kapetanovic (2018) argue: "the success of Dubai's economic development is owed to its small, open, well-integrated economy into the global economic and financial system" (p.90). Thus, the emirate has developed a conducive ecosystem for innovation in financial services, which is a key part of Dubai's effort to diversify its economy.

For over 15 years Dubai is the reference city of the UAE for the World Bank's Doing Business Index (World Bank Group, 2020). Its ranking has improved continuously over the last decade (World Bank Group, 2020). The emirate aims to be an attractive destination for investment and entrepreneurs through its robust infrastructure and advanced digital technologies.

Fintech is undergoing tremendous growth in Dubai and its rise seems unstoppable since 2019. Fintech startups in the UAE began in the payments and crowdfunding sectors and have grown to service the wide entrepreneurial and SME base across the Middle East (Clifford Chance, 2017, p.6). Today, across the Arab World, the UAE has the most developed and dynamic fintech ecosystem (Fintechnews Middle East, 2021).

Dubai's financial service sector represents the third-largest economic driver, accounting for over $10 \%$ of its gross domestic product (GDP). The emirate has established itself as an integral component of global financial services thanks to its dynamic onshore and offshore markets. Dubai is home to one of the nation's two financial centers.

The Dubai International Financial Centre (DIFC) has reached a global hub status for financial services, strengthening its position as one of the top 10 fintech hubs in the world. DIFC is governed by three independent bodies: the DIFC Authority, the Dubai Financial Services Authority, and the Dispute Resolution Authority. In particular, DIFC's financial ecosystem, which focuses on innovation, has achieved a high degree of sophistication and diversity. Since 2019, Dubai's fintech ecosystem more than doubled. In 2020, amid of the COVID-19 pandemic, DIFC also doubled its fintech and innovation firms to 303 . The fintech sector increased at an annual growth rate of over 30\%. By 2020, the DIFC recorded more than 2,500 active registered companies operating in the Centre (Fintechnews Middle East, 2021). Moreover, already in March 2021, a total of 915 financial companies were active in DIFC (Government of Dubai Media Office, 2021). In September 2021, the DIFC as a leading international financial hub in the MEASA region verified its progress in achieving the targets of its "2024 Strategy". In fact, in the first half of 2021, DIFC delivered strong growth, with 492 new company registrations, an impressive 59\% increase from the same period in 2020, (Note 6) confirming the good condition of Dubai financial and innovation system.

Dubai's dynamic fintech ecosystem is instrumental in the growth of the fintech industry and fintech startups are at the heart of this ecosystem. Furthermore, Dubai is a major fintech hub for startups in the Middle East and North Africa (MENA) and represents a fast-growing startup ecosystem. As Zarrouk, El Ghak, \& Bakhouche (2021, p.3) underline, three factors have made the ecosystem favorable for determining the UAE (and Dubai) as a leading fintech hub in the wider MENA region: (1) the government is at the center of efforts to drive 
innovation as part of a larger vision; (2) the UAE's ecosystem is conducive to new financial alternatives; and (3) continuous initiatives and policies are implemented to attract international human capital as an effective tool to stimulate innovation domestically through spillover effects.

In 2020, Dubai startups attracted over half of the venture funding invested in the UAE-based startups. Also, Dubai is at the forefront in adopting digital technologies like mobile technology, social technology, cloud computing, machine-to-machine communication, and big data analytics. The emirate is a prime mover in implementing emerging technologies and incubating high-technology startups. Its undergoing digital transformation has highlighted the contribution of AI, robotics, machine learning, and blockchain used both in the business world and as tools to combat COVID-19. Moreover, Dubai, thanks to its blockchain strategy, has given blockchain technology a boost providing a powerful tool for simple, safe, and secure transactions; also, proving that Dubai owns a developed and innovative digital infrastructure. According to Schilirò (2020), this infrastructure is more important than ever to address the digital globalization phenomenon.

Several surveys (e. g. Clifford Chance, 2017; Fintechnews Middle East, 2021) point out that the factors contributing to fintech growth in Dubai include: (1) a tech-savvy population that adopts fintech innovations; (2) a flourishing of innovative fintech startups that have revolutionized the entire financial services sector; (3) a private sector interested in partnering with innovative fintech startups; (4) a dedicated and well-suited regulatory system; and (5) supportive government policies.

Indeed, government (e.g., financial regulators and legislation) plays a key role in a fintech ecosystem. Regulators in Dubai tend to create a favorable regulatory environment for fintech, helping fintech startups stimulate fintech innovation and facilitate global financial competitiveness. In the direction of a favorable regulatory environment go the law amendments taken by the Federal Government on January 30, 2021, which allow granting Emirati citizenship to investors. Another significant legislative decision by the UAE cabinet, on March 21, 2021, is the approval of the Virtual Visa, which is a new visa category that enables people to work online from Dubai irrespective of their office location. The attraction of specialized talents and professionals are examples of a supporting policy that will impact the landscape of financial services in Dubai and the UAE. These proactive government actions will benefit Dubai and the UAE, as well as their investment and financial environments as highlighted by Zarrouk, El Ghak, \& Bakhouche (2021).

To grasp the dynamism of the financial sector in Dubai, think about how the bank fintech base is expanding, which also adopts fintech solutions. In the last five years, Dubai pioneered the launch of several online-only banks to target consumers, including Emirates NBD's Liv, Commercial Bank of Dubai's CBD NOW, and Mashreq Neo. Meanwhile, DIFC has moved on the global scene by strengthening its fintech ecosystem, including global and regional fintech firms (e.g., Ebury, Ripple, Adyen, KoFax ME, and Tabby).

Most impressive, however, is that the adoption of digital technologies, startups, and new initiatives has pushed digitization into financial services, where fintech is the key area of this disruptive change. Fintech has also become one of the most attractive sectors for investors, a trend that has characterized this sector for several years. During 2020, significant flows of investments and foreign direct investment (FDI) arrived in the Dubai fintech ecosystem. In particular, in the first half of that year, it attracted $\$ 3.26$ billion in FDI through 190 projects, according to the Dubai Investment Development Agency. Currently, Dubai is home to more than 50\% of fintech companies in the Middle East, Africa, and South Asia (MEASA) region (with a population of around 3 billion people). Therefore, Dubai aims to foster the creation of new and innovative pro-tech platforms to meet the financial needs of such a huge market.

In Dubai, most fintech startups focus on digital payments, online lending, and remittances. Digital payments through cryptocurrencies and digital tokens represent disruptive factors for fintech; they are a game-changer in financial systems as they boost new platforms and investment opportunities (Dubai Future Foundation, 2020b). Digital tokens fractionize and represent any kind of asset, including equities or bonds, real estate, and commodities, which provides them with a high level of versatility compared to traditional systems. Cryptocurrencies are decentralized currencies, meaning that their transfer takes place without the passage of a third party. Their implementation is based on the principles of cryptography to validate transactions and the generation of the same currency. Since the beginning of the pandemic, cryptocurrencies saw a surging global demand. Despite price volatility and value instability, cryptocurrencies experienced impressive growth and interest in emerging markets. In May 2021, the Dubai Multi Commodities Centre (DMCC) launched the DMCC Crypto Centre, a comprehensive ecosystem for businesses operating in the cryptographic and blockchain sectors. The Centre emphasizes the importance of an ecosystem that provides access to capital, resources, and opportunities to crypto firms to support crypto businesses and advance global trade. 
Mueller \& Piwowar (2019) highlights that fintech firms in the UAE focus on remittances because in the country, particularly in Dubai, the growing number of expatriate workers transfers billions of dollars to their countries of origin. (Note 7) Thus, most investment is concentrated in the payments space (i.e., payments, transfers, and remittances). In Dubai, the focus on the payment sector, which attracts most of the funding in new fintech firms, is explained by the wide adoption of mobile broadband and mobile cellular telephones.

DIFC plays a leading role in developing and strengthening the fintech ecosystem in Dubai. In 2017, DIFC launched FinTech Hive, the first and largest financial technology accelerator in the MEASA region, where both fintech and financial institutions are housed under one roof. FinTech Hive gives fintech firms and other tech companies (i.e., Insurtechs, Regtechs, and Islamic Fintechs) access to accelerator programs and mentorship from leading financial institutions and insurance partners. Furthermore, in January 2020, DIFC FinTech Hive launched FinTech Hive Scale Up, a new funding accelerator program for fintech start-ups in the MEASA region (DIFC, 2020). This program aims to benefit startups by helping them grow through strategic partnerships and receiving investment resources through the DIFC FinTech Hive ecosystem. Also, since 2020, another initiative by FinTech Hive is Accelerate Her that promotes a female-focused career mentorship accelerator program to empower women in financial services. The program aims to support gender diversity within the financial community by equipping young, aspiring female executives with tools and experience to broaden their knowledge and reach in the financial industry.

In addition, the DIFC Innovation Hub, as a major pillar of the Dubai Future District, represents the region's largest and most comprehensive technology ecosystem, providing education, training, and both incubator and accelerator programs. (Note 8) The DIFC Innovation Hub aims to bring the fintech and innovation community together to shape the future of finance in the UAE. In May 2021, the DIFC Innovation Hub was enlarged so that the Hub will be home to more than 1,000 companies.

Fintechnews Middle East (2021, p.5) provides a map of the UAE fintech landscape in 2021. This map enumerates a total number of 134 fintech companies distributed among the 16 fintech categories (Payment, Insurtech, Ewallet, Lending, Blockchain / Cryptocurrency, Wealthtech, Digital banking / Neobanks, Open Banking, Remittance, Data / AI, etc.)

Over the past five years, the fintech environment and fintech firms in Dubai have grown considerably. Some of these companies (e.g., FlexxPay, Go Rise, Sarwa, Beehive, and NOW Money) were born thanks to investments by the DIFC's Fintech Fund, a US $\$ 100$ million fund for fintech startups. Most investments in fintech are aimed at the transformation of the entire business model. Others want to ensure greater levels of efficiency rather than substantial innovation. Preferred technologies in investments include AI, big data, DLT, API, technologies for integration, and robots. Some fintech ventures have raised huge funding by global venture capital (VC) companies. VCs are paying great attention to fintech startups in Dubai, as these firms provide innovative fintech solutions that add substantial value to any sector. At the same time, VCs, with their deep pockets, can support these startups, as most of the latter cannot survive without large funding (Zarrouk, El Ghak, \& Bakhouche, 2021). Fintech is often a volume game.

To conclude, the analysis in this section shows that Dubai has a dynamic fintech sector, which is growing both in the number of firms and in terms of innovation. As mentioned, financial technologies recorded a rapid growth during 2020, proving the sector's resilience amid COVID-19 (Dubai Future Foundation, 2020a). In 2020, the DIFC experienced its best annual performance with a $24 \%$ increase in the number of licensed firms that provide financial services (Government of Dubai Media Office, 2021). Recent data shows that the trend is strengthening in 2021 (Fintechnews Middle East, 2021). In Dubai, the financial technology sector is one of the most developed in comparison to other business sectors. The DIFC is key to guaranteeing fintech firms and startups a dynamic ecosystem and strong support for innovation. At the same time, fintech firms show strong customer retention. In addition, regulation and legal frameworks, critical to ensuring a safe financial environment, are an ongoing challenge for fintech in Dubai.

\section{Regulations and Regulators of Dubai's Financial Services}

The previous section also pointed out that regulators in Dubai aim to create a favorable regulatory environment for fintech as Dubai continues to see rapid change in its fintech ecosystem.

Zarrouk, El Ghak, \& Bakhouche (2021) highlight the importance of the regulatory environment in favoring or hindering the creation and growth of fintech ventures. These authors point out that the UAE, including Dubai, has a favorable regulatory framework that embraces the creation of innovation and implements policies to encourage growth in the fintech sector. However, Mueller \& Piwowar (2019) warn about the divergence between mainland and free zone governance in the UAE, pointing to the need for a uniform regulatory mechanism for 
both.

Furthermore, Capgemini (2020), Dolman \& Joachim (2020), and Mehrban et al. (2020) underline the crucial role of a clear legal framework, as well as the importance of regulations and policies to offset the risks inherent in fintech business, such as cybersecurity, data privacy, and data protection.

In Dubai, regulations of financial services are under the control of several regulators. These include the Central Bank, the Dubai Financial Services Authority (DFSA), and the UAE Securities and Commodities Authority (SCA). The Central Bank of UAE regulates all financial service providers and handles the licensing and regulation of the domestic banking system, including both national and foreign banks. In turn, the institutions based in the DIFC's offshore banking sector are subject to a distinct legal environment overseen by the DFSA. In general, the DFSA regulates financial and ancillary services conducted in or from DIFC.

Regulators are constantly updating regulations to match the evolution of financial services and technology innovation in the emirate. The regulatory environment and legislative decisions by the government aim to facilitate the financial competitiveness of Dubai as a global financial hub. In particular, in December 2020, the Central Bank of UAE launched its fintech office to support fintech activities in the banking sector and facilitate the establishment of a UAE-approved regulatory framework in cooperation with other fintech authorities in the UAE. The new office aims to develop a mature fintech ecosystem within the UAE and help to attract international and regional fintech companies as well as provide a platform for all market participants to collaborate and innovate (Fintechnews Middle East, 2021).

Moreover, DIFC's regulations and laws reflect global best practices. In this perspective, the government of Dubai enacted the Data Protection Law N.5, which came into force on July 1, 2020. This law brought the DIFC's data protection regime in line with global data protection and international data privacy standards.

To strengthen cybersecurity, DFSA launched the Cyber Threat Intelligence Platform in January 2020. This was the first regulator-led platform of this kind in the region, creating an information-sharing system for firms in DIFC through public-private partnerships. The platform is designed to strengthen the cyber security environment in the DIFC and help firms implement appropriate safeguards to mitigate cyber risks.

Regarding fintech, regulators have an important role to play by formulating standards and ensuring financial market stability. Innovation is encouraged through sandboxes and new licenses. Sandbox environments are free from legal consequences in which fintech firms can test and validate business models without draining their resources by attempting to obtain traditional financial licenses. This also protects them from new forms of illegal activities (Teigland et al., 2018). Cornelli, Doerr, Franco \& Frost (2021) find that regulatory sandboxes spur entry in the fintech sector. Mueller \& Piwowar (2019) also underline the importance of sandboxes to attract local and international fintech startups and address innovation-related challenges. However, these authors detect that, in implementing sandbox frameworks, it is difficult to determine what success looks like and how to measure it due to the lack of a standardized set of metrics used by regulators.

In Dubai, the DFSA aims to support innovation that leads to more efficient markets and positive outcomes for consumers and users of financial services. (Note 9) In this regard, the DFSA runs a licensed sandbox, launched in 2017, called 'Innovation Testing License (ITL) Program' to help fintech firms test innovative solutions and concepts. In particular, tests of concepts are primarily based on blockchain technologies within the DIFC.

Furthermore, in August 2020 DIFC launched a new Innovation License, a collaboration with the Dubai Future Foundation to drive blockchain and AI-driven startups in the financial sector.

Regarding crypto regulation, the UAE DMCC established the onshore crypto assets regulation framework with the SCA. In addition, the SCA regulates cryptocurrencies in a free zone. The SCA published crypto assets legislation on November 1, 2020. (Note 10) The SCA endeavors to ensure the protection of investors dealing in crypto assets while avoiding money laundering activities. Another major federal law was enacted by decree in October 2020 to establish the transfer of all operational and executive powers and competencies from the SCA to licensed securities and commodities markets, while the SCA maintains the regulation and supervision of local financial markets. Related to this law and in the same period, the UAE Central Bank issued a regulation on stored value facilities (SVF). This regulation aims to facilitate fintech firms and non-bank payment service providers with easier access to the UAE market. In addition, it wants to continue to safeguard customers' funds, ensure proper business conduct, and support the development of payment products and services.

In January 2021, the UAE Centre for the Fourth Industrial Revolution (C4IRUAE) signed a partnership with Dubai International Financial Centre Authority (DIFC) and Dubai Financial Services Authority (DFSA), unveiling a pilot sandbox, which could eventually lead to the full licensing in the digital assets and blockchain 
sector. This initiative is one of those carried out by regulators and government agencies to embrace to tokenization and blockchain (Fintechnews Middle East, 2021).

Furthermore, the DFSA has implemented the Regulatory Law Amendment Law, DIFC Law No. 1 of 2021, which was proposed to facilitate DLT-based activities. (Note 11) The initiative is making a transparent and certain path for issuers who wish to raise capital in or from the DIFC using DLT and similar technology. Also, it assists those firms who intend to be involved in this market by conducting or providing financial services. Finally, in July 2021, the DFSA announced tokenization regulation. The security token regulation will cover the issuance, trading, custodial services, marketing, and secondary market exchanges. Major changes related to the offer of security tokens to the public and admission to trading of security tokens on trading facilities, the trading of security tokens, and the provision of other financial services relating to security tokens.

Overall, Dubai is implementing a proactive regulatory environment to favor the development of the fintech industry and fintech startups, as well as serving as an incubator of the fintech ecosystem.

\section{Discussion and Conclusions}

After an extensive although not exhaustive analysis of fintech literature, this paper focused on the development of fintech and the fintech ecosystem in Dubai. Thanks to the role of DIFC, which supports tech startups and innovation, Dubai has a dynamic ecosystem and its fintech sector has grown at a double-digit rate even in 2020 despite the Covid-19 pandemic.

Fintech development is linked to the progress of digital innovation. In addition, fintech plays an important role in generating new and transformative solutions, which establishes innovative financial services.

Several empirical investigations on fintech (Capgemini, 2020; Deloitte, 2020; Mehrban et al., 2020; Dolman \& Joachim, 2020) show that the entry of fintech companies has revolutionized the world of financial services. These companies, through the adoption and integration of innovative technologies (e.g., technologies related to mobile networks, cloud computing, big data, data analytics techniques, etc.), have increased the range of services offered to companies, consumers, and savers. In Dubai, fintech has fostered progress and made extensive use of disruptive technologies like AI and blockchain.

This paper highlighted that Dubai's new digital financial services exponential growth is mainly due to consumers' needs for easy access to payment services. Fintech firms operate in a context where demands change in real time and consumer expectations change quickly. The unbundling and decentralized nature of fintech firms play a fundamental role in reshaping the financial industry, particularly banks. Dubai's agile and flexible ecosystem allows banks to adapt to the new digital environment. Banks in the emirate appear to be able to forge partnerships with fintech startups and respond to the need for quick solutions with easier banking activities.

Fintech firms face many challenges and opportunities in this dynamic environment. Risks exist alongside opportunities due to the diffusion of fintech. Those related to cybersecurity and data privacy are of major concern. Privacy protection is one of the most significant and critical aspects of fintech operations. A key challenge for fintech development is to find the right balance between regulation and promotion.

To conclude, fintech is reshaping finance. The effects vary significantly depending on the regulatory system, readiness, and strength of local fintech ecosystems. Dubai is at the forefront of this disruptive change. Also, regulatory authorities encourage innovation and competition to fintech firms, particularly fintech startups. In addition, they provide instruments for data protection and fraud detection. In the Dubai fintech ecosystem, fintech startups tend to introduce new ways of assessing risk through AI and digital technologies, like blockchain, which attract investors and make Dubai financial system a challenging paradigm for the business world.

\section{Acknowledgments}

I wish to thank David Carfi and Alessia Donato for their useful observations. I wish also to thank the anonymous referees for the helpful comments. The usual disclaimer applies.

\section{References}

Agur, I., Martinez Peira, S., \& Roschon, C. (2020). Digital Financial Services and the Pandemic: Opportunities and Risks for Emerging and Developing Economies. IMF Research, July 1, 2020.

Alaassar, A., Mention, A. L., \& Aas, T. H. (2021). Ecosystem dynamics: exploring the interplay within fintech entrepreneurial ecosystems. Small Bus. Econ., 13 May 2021. https://doi.org/10.1007/s11187-021-00505-5

Breidbach, C. F., Keating, B. W., \& Lim, C. (2020). Fintech: research directions to explore the digital transformation of financial service systems. Journal of Service Theory and Practice, 30(1), 79-102. 
https://doi.org/10.1108/JSTP-08-2018-0185

Brown, R., \& Mason, C. (2017). Looking inside the spiky bits: A critical review and conceptualisation of entrepreneurial ecosystems. Small Bus. Econ., 49(1), 11-30. https:// doi. org/ 10. 1007/ s11187- 017- 9865-7

Capgemini. (2020). The World FinTech Report 2020. Retrieved from https://fintechworldreport.com/

Clifford Chance. (2017). Fintech in the Middle East. An Overview. London: Clifford Chance, October.

Cornelli, G., Doerr, S., Franco, L., \& Frost, J. (2021). Funding for fintechs: patterns and drivers. BIS Quarterly Review, September, 31-43.

Deloitte. (2020). Fintech. On the brink of further disruption. Amsterdam: Deloitte, The Netherlands.

DIFC. (2020). DIFC's FinTech Hive Reveals 'Scale Up Programme' for FinTech startups. Press Release 22 JAN 2020. Retrieved from https://www.difc.ae/newsroom/news/difcs-fintech-hive-reveals-scale-up-programme-fintech-startups/

Dolman, A., \& Joachim, S. B._(2020). Fintech 2020. A Global Survey on the State of Financial Technology. Boston, MA: Goodwin, September.

Dubai Future Foundation. (2020a). Life after COVID-19: Financial Technologies. Dubai: Dubai Future Foundation, May.

Dubai Future Foundation. (2020b). Tokenization and digital assets. A Transformative approach towards investments. Dubai: Dubai Future Foundation, November.

Fintechnews Middle East. (2021). UAE Fintech Report 2021. UAE: Fintechnews Middle East.

Goldstein, I., Jagtiani, J., \& Klein, A. (2019). Fintech and the New Financial Landscape. Banking Perspective Quarter, 1, 64-71.

Gomber, P., Kauffman, R. J., Parker, C., \& Weber, B. W. (2018). On the Fintech revolution: interpreting the forces of innovation, disruption, and transformation in financial services. Journal of Management Information Systems, 35(1), 220-265. https://doi.org/10.1080/07421222.2018.1440766

Gomber, P., Koch, J. A., \& Siering, M. (2017). Digital Finance and FinTech: Current research and future research directions. Journal of Business Economics, 87(5), 537-580. https://doi.org/10.1007/s11573-017-0852-x

Government of Dubai Media Office - 07 September 2021. Retrieved from https://www.difc.ae/newsroom/news/dubai-international-financial-centre-continues-strong-growth-h1-2021/

Government of Dubai Media Office. (2021). DIFC records highest number of annual registrations since inception in 2020. Press Release, 09 MAR 2021. Retrieved from https://www.difc.ae/newsroom/news/difc-records-highest-number-annual-registrations-inception-2020/

Gozman, D., Liebenau, J., \& Mangan, J. (2018). The innovation mechanisms of fintech start-ups: Insights from SWIFT's innotribe competition. Journal of Management Information Systems, 35(1), 145-179. https://doi.org/10.1080/07421222.2018.1440768

Haddad, C., \& Hornuf, L. (2019). The emergence of the global fintech market: economic and technological determinants. Small Bus. Econ., 53, 81-105. https://doi.org/10.1007/s11187-018-9991-x

Iman, N. (2020). The rise and rise of financial technology: The good, the bad, and the verdict. Cogent Business \& Management, 7, 1725309, 1-17. https://doi.org/10.1080/23311975.2020.1725309

Lee, I., \& Shin, Y. J. (2018). Fintech: Ecosystem, business models, investment decisions, and challenges. Business Horizon, 61, 35-46. https://doi.org/10.1016/j.bushor.2017.09.003

Lukonga, I. (2018). Fintech, Inclusive Growth and Cyber Risks: Focus on the MENAP and CCA Regions. IMF Working Paper, WP/18/201, Middle East and Central Asia Department, 1-52. https://doi.org/10.5089/9781484374900.001

Mehrban, S., Waqas Nadeem, M., \& Hussain, M. et al. (2020). Towards Secure FinTech: A Survey, Taxonomy, and Open Research Challenges. IEEE Access, 8, 23391-23406. https://doi.org/10.1109/ACCESS.2020.2970430

Mishrif, A., \& Kapetanovic, H. (2018). Dubai's Model of Economic Diversification. In Economic Diversification in the Gulf Region, Volume II. Comparing Global Challenges. A. Mishrif, \& Y. Al Balushi (Eds.), London: Palgrave Macmillan, 89-111. https://doi.org/10.1007/978-981-10-5786-1_5

Mueller, J., \& Piwowar, M. S. (2019). The rise of fintech in the Middle-Est. September 19, 2019. Washington 
D.C.: Milken Institute.

OECD. (2020). Digital disruption in banking and its impact on competition. Paris: OECD.

Pousttchi, P., \& Dehnert, M. (2018). Exploring the digitalization impact on consumer decision-making in retail banking. Electronic Markets, 28(3), 265-286. https://doi.org/10.1007/s12525-017-0283-0

Schilirò, D. (2013). Diversification and development of the United Arab Emirates' economy. Journal of Applied Economic Sciences, VIII(2), 228-239.

Schilirò, D. (2020). Towards Digital Globalization and the Covid-19 Challenge. International Journal of Business Management and Economic Research, 11(2), 1710-1716.

Teigland, R., Siri, S., Larsson, A., Puertas, A. M., \& Bogusz, C. I. (2018). Introduction: FinTech and shifting financial system institutions. In Teigland, R., Siri, S., Larsson, A., Puertas, A. M., \& Bogusz, C. I. (Eds.), The Rise and Development of FinTech: Accounts of Disruption from Sweden and beyond. London: Routledge, 1-18. https://doi.org/10.4324/9781351183628-1

World Bank Group. (2020). Doing Business 2020. Washington, DC: International Bank for Reconstruction and Development / The World Bank.

Zarrouk, H., El Ghak, T., \& Bakhouche, A. (2021). Exploring Economic and Technological Determinants of FinTech Startups' Success and Growth in the United Arab Emirates. Journal of Open Innovation: Technology, Markets and Complexity 7(50), 1-24. https://doi.org/10.3390/joitmc7010050

Zhang, B., Baeck, P., Ziegler, T., Bone, J., \& Garvey, K. (2016). Pushing Boundaries. The 2015 UK alternative finance industry report. 16 February 2016. University of Cambridge Judge Business School: Cambridge Center for Alternative Finance. https://doi.org/10.2139/ssrn.3621312

\section{Notes}

Note 1. Alaassar, Mention, \& Aas (2021) carry out an empirical-qualitative survey of EE fintech in Singapore.

Note 2. An API is a set of rules and specifications that software programs follow to communicate with one another and exchange data directly without the need for human input, and an interface between different software programs that facilitates their interaction. (OECD, 2020).

Note 3. In large parts of Asia, fintech firms are threatening the business models of traditional banks. In China, for instance, WeChat Pay and Alipay are responsible for more than half of all payment processes in the country.

Note 4. In Europe, for example, open banking is implemented through the Payment Services Directive 2 (PSD2) (Directive (EU) 2015/2366), which sets a common legal framework for businesses and consumers.

Note 5. The demand for more accessibility has also led to electronic trading of securities due to the development of IT. A further step toward accessibility is the process of tokenization, which recognizes either existing securities or new assets on a blockchain or DLT.

Note 6. Government of Dubai Media Office - 07 September 2021.

Note 7. The UAE expatriate population represents roughly $90 \%$ of the country's total population.

Note 8. Dubai's Innovation Hub is in Dubai Internet City. It aims to nurture tech startups and SMEs.

Note 9. DFSA is also part of the Global Financial Innovation Networks (GFIN), a community of regulators that offers testing opportunities across international jurisdictions to fintech firms. This facilitates entry into overseas markets.

Note 10. The UAE's Securities and Commodities Authority (SCA) published "The Authority's Chairman of the Board of Directors Decision No. (21/R.M) of 2020 Concerning the Regulation of Crypto Assets."

Note 11. See https://dfsaen.thomsonreuters.com/rulebook/notice-amendments-legislation-april-2021

\section{Copyrights}

Copyright for this article is retained by the author(s), with first publication rights granted to the journal.

This is an open-access article distributed under the terms and conditions of the Creative Commons Attribution license (http://creativecommons.org/licenses/by/4.0/). 